\title{
Visual imagery vs. semantic category as encoding conditions
}

\author{
HERBERT F. CROVITZ and MICHAEL T. HARVEY \\ Veterans Administration Hospital, Durham, North Carolina 27705
}

\begin{abstract}
Semantic encoding was directly compared to visual imagery encoding in an experimental variant of the Craik-Tulving procedure. Sixty words were presented orally in one of five encoding conditions. Two conditions were from Experiment 9 of Craik and Tulving (1975), that is, semantic category/yes and semantic category/no. Three conditions were imagery encoding conditions: single image/good, single image/bad, and interactive imagery relating pairs of words. The results for the college students tested indicate that imagery encoding gave better immediate recognition than did deep semantic encoding. Generally, recognition scores did not differ from one another within the imagery conditions, but within the semantic conditions, semantic category/yes gave higher recognition scores than did semantic category/no. The findings call for further investigation of the cognitive processes relevant to semantic as compared to imagery encoding.
\end{abstract}

Hoffman and Senter (1978) review a tradition interested in imagery transformation at encoding of tobe-remembered material, and Craik and Tulving (1975) represent a tradition interested in semantic encoding of to-be-remembered material. The present experiment is designed to make a direct comparison between encoding conditions representing these two areas of research.

Craik and Tulving (1975, Experiment 9) presented a list of 60 words, one by one, on a projection screen with $6 \mathrm{sec}$ separating successive words. The subjects were members of an undergraduate class who were asked to mark answers to questions of three kinds concerning specific words: case (Is the work printed in capital letters?), rhyme (Does the word rhyme with stopper?), and category (Is the word a kind of fruit?). After the list was presented, subjects were asked to check exactly 60 of the words on a larger list as old; the 60 words given were imbedded among 120 distractor items. There was a clear superiority of recognition for items that had been presented with category questions, with some advantage for words that led to "yes" answers as compared to those that led to "no" answers (e.g., "Is the word a kind of fruit?" when the word was "Apple," as compared to "Is the word a kind of fruit?" when the word was "Hammer.")

Crovitz, Harvey, and Horn (in press) asked participants to encode lists of words using the simple imagery instruction to "Picture [this item] and [that item] together." Word lists encoded with the use of this instruction were better recalled than word lists with the instruction to "remember the words any way you want."

This research was supported by the Medical Research Service of the Veterans Administration. We thank Harold Schiffman of Duke University for allowing us to test his statistics class.
The following experiment used the salient features of these studies in order to compare recognition of verbal items using category/yes and category/no items as representative of deep semantic encoding and variants of the "picture" instruction as representative of visual imagery encoding.

\section{METHOD}

\section{Subjects}

Thirty students in an undergraduate statistics class at Duke University participated in the experiment.

\section{Material}

Sixty words from the list of basic English picturable things (Ogden, 1938) were randomly selected as stimuli. An answer sheet was prepared in which the 60 stimulus words were imbedded randomly among 100 distractor words. The distractors were also from the list of basic English picturable things. Only 100 distractors, rather than 120 , as in Craik and Tulving (1975), were used in order to avoid the occurrence of homonyms at presentation and the occurrence of synonyms at reading of the answer sheet.

The 60 stimulus words were randomly presented in sentences that instructed encoding in five different processing conditions. Two were the same as in Craik and Tulving (1975), namely, semantic category/yes (e.g., Is a mouth a part of the body?) and semantic category/no (e.g., Is an island a type of fish?). Three conditions were imagery encoding conditions: single image/good (e.g., Picture a good orange), single image/bad (e.g., Picture a bad potato), and interactive imagery [e.g., Picture a collar (first word) and a snake (second word) together] .

\section{Procedure}

Participants were instructed to prepare a sheet of paper numbered from 1 to 50 . During presentation of the instruction sentences, they were either to make a check mark after making an image or to write yes or no in response to category questions at the appropriate numeral. Participants were tested in a single group, with sentences read aloud by the experimenter at the rate of one sentence every $6 \mathrm{sec}$. Immediately after presentation of the 50 instruction sentences, participants were given answer 
sheets and instructed to check exactly 60 words as those that had been presented.

\section{RESULTS AND DISCUSSION}

Table 1 shows the mean recognition score for each of the semantic and imagery conditions, as well as the differences between the means. A one-way withinsubjects analysis of variance found the encoding conditions to be a significant variable $[F(5,155)=11.24$, $p<.001]$. It can be seen that generally the imagery conditions led to higher recognition scores than did the semantic conditions. Within the imagery conditions, recognition scores generally did not differ from one another; within the semantic conditions, the semanticcategory/yes condition gave higher recognition scores than the semantic-category/no condition, as consistent with Craik and Tulving (1975).

Thus, in this experiment, which pitted semantic encoding against imagery encoding, there was no advantage for recognition in favor of deep semantic encoding under the instruction to answer category questions as compared to imagery encoding under the instruction to make pictures. Adaptations of the Craik-Tulving paradigm appear to be a convenient method for testing the relative effects on recognition of various encoding instructions. In light of the present findings, some work needs to be done to clarify further the similarities and differences between cognitive mechanisms brought into play by various encoding instructions (Kosslyn \& Pomerantz, 1977; Pylyshyn, 1973).

\section{REFERENCES}

Craik, F. I. M., \& Tulving, E. Depth of processing and the
Table 1 Mean Recognition Score and Mean Differences

\begin{tabular}{|c|c|c|c|c|c|c|}
\hline & \multicolumn{6}{|c|}{ Encoding Conditions } \\
\hline & \multicolumn{2}{|c|}{$\begin{array}{l}\text { Interactive } \\
\text { Image }\end{array}$} & \multicolumn{2}{|c|}{$\begin{array}{l}\text { Single } \\
\text { Image }\end{array}$} & \multicolumn{2}{|c|}{$\begin{array}{l}\text { Semantic } \\
\text { Category }\end{array}$} \\
\hline & $\begin{array}{l}\text { Word } 1 \\
\text { ITI1 }\end{array}$ & $\begin{array}{l}\text { Word } 2 \\
\text { ITI2 }\end{array}$ & $\begin{array}{l}\text { Good } \\
\text { SIG }\end{array}$ & $\begin{array}{l}\text { Bad } \\
\text { SIB }\end{array}$ & $\begin{array}{l}\text { Yes } \\
\text { SCY }\end{array}$ & $\begin{array}{l}\text { No } \\
\text { SCN }\end{array}$ \\
\hline $\begin{array}{l}\text { Mean } \\
\text { ITI1 } \\
\text { ITI2 } \\
\text { SIG } \\
\text { SIB } \\
\text { SCY } \\
\text { SCN }\end{array}$ & 8.27 & $\begin{array}{r}8.80 \\
-.53\end{array}$ & $\begin{array}{l}9.17 \\
-.90 * \\
-.37\end{array}$ & $\begin{array}{r}8.87 \\
-.60 \\
-.07 \\
.30\end{array}$ & $\begin{array}{l}7.63 \\
.64 \\
1.17^{* *} \\
1.54^{* *} \\
1.24^{* *}\end{array}$ & $\begin{array}{l}6.67 \\
1.60^{* *} \\
2.13^{* *} \\
2.50^{* *} \\
2.20^{* *} \\
.96^{*}\end{array}$ \\
\hline
\end{tabular}

Note-There were 10 words presented per encoding condition.

*Difference between means significant at .05 level.

**Difference between means significant at .01 level.

retention of words in episodic memory. Journal of Experimental Psychology: General, 1975, 104, 268-294.

Crovitz, H. F., Harvey, M. T., \& Horn, R. W. Problems in the acquisition of imagery mnemonics: Three brain-damaged cases. Cortex, in press.

Hoffman, R. R., \& Senter, R. J. Recent history of psychology: Mnemonic techniques and the psycholinguistic revolution. Psychological Record, 1978, 28, 3-15.

Kosslyn, S. M., \& Pomerantz, J. R. Imagery, propositions, and the form of internal representations. Cognitive Psychology, $1977,9,52-76$.

OGden, C. K. The system of basic English. New York: Harcourt, Brace \& World, 1938.

Pylyshyn, Z. What the mind's eye tells the mind's brain: A critique of mental imagery. Psychological Bulletin, 1973, 80, 1-24.

(Received for publication January $31,1979$. 